\title{
[ 493$]$
}

XXVIII. An Account of the Mode of Growth of young Corals of the Genus Fungia. By Mr. Samuel Stutchbury, A.L.S.

Read January 19, 1830.

As I trust that the Linnean Society will receive favourably any new observations upon natural history, I beg permission to lay before them the following facts in regard to the young state of corals of the genus Fungia, which I met with in the Society Islands and the Paumotu's or Low Islands forming part of the Dangerous Archipelago.

Having a strong wish to travel and see the productions of nature in tropical climates, $I$ agreed to accompany a voyage undertaken by a company formed in the year 1825, for the purpose of fishing for pearls in the Pacific Ocean. My engagement was as a collector in natural history.

On our arrival at Tahiti a number of natives of that island were (as is generally the practice in such voyages) engaged as divers, and we proceeded to the Dangerous Archipelago, which is one of the best grounds for the pearl fishery in the Pacific.

The specimens of Fungia which $\mathbf{I}$ have seen, generally lie in hollows of the reefs, where they are in some degree protected from the more violent agitation of the sea by the surrounding portions of branching coral, which inclose the hollows and, at the same time, allow sea water free access through their interstices.

It appears, that although the older and larger individuals are quite unattached and present no mark of former attachment, yet 
that in the young state they are fixed sometimes to rocks, and frequently to the dead remains of one of their own species. In this state they grow upon a footstalk, and generally remain attached till they acquire the size of nearly an inch in diameter, when they separate at the top of the peduncle*.

At this time the coral, when divested of the fleshy part, shows a circular opening beneath, through which the radiating plates of the upper surface are visible. In a short time a deposit of coral matter takes place, which cicatrizes the opening, the marks of which however can be traced for a considerable time; at length the increase of this deposit, which continues with the growth of the animal, entirely obliterates all appearance of it. It will not appear surprising that this circumstance should hitherto have been unnoticed, when it is recollected that it has very rarely occurred to naturalists to visit the places of their growth, and that to general collectors the smaller specimens would appear hardly worth the trouble of preserving and bringing home.

The sheltered situations in which the Fungice are found are peculiarly well adapted to their nature, as they would be liable to injury if they were exposed to the full force of a stormy sea; and the circumstance of their being attached in the young state is a beautiful provision of Nature for their preservation at that period, as from their light weight when first developed they

* The following is extracted from my Journal written at the time.

"Thursday, January 4, 1827.-This day went to the reefs with two natives to collect some specimens of the Madrepora fungites. Succeeded in obtaining one specimen, which illustrates a fact respecting their growth. This is a dead coral having a number of young living corals attached to it by a pedicle : thus it appears that, when very young, they are attached until about the size of a shilling; you may then perceive a line of demarcation, at which mark the larger ones are easily separable, the lower portion being dead. Thus it would appear that an action takes place similar to sloughing, the larger corals of this genus having no trace left of attachment. These corals appear to inhabit very shallow water."

would, 
would, if unattached, be exposed to great injury even by a slight agitation of the water.

I have also to remark upon this fact, that the Fungice while attached agree in every respect with Lamarck's genus Caryophyllia, more especially in their early state, when the radiating plates are first developed. At this time their upper discs are scarcely larger than the stem, but they soon begin to spread and show indications of their characteristic form.

There are not unfrequently instances of smaller individuals remaining fixed to large ones in a living state, and such specimens are not unfrequent in collections of corals; but in all such cases that I have seen, the younger ones are attached to the under side of the old one, and I believe them to be cases of accidental attachment.

I consider the specimens found at 'Tahiti, which are figured in the accompanying plate, to belong to Lamarck's species of Fungia agariciformis, of which there appear to be many varieties. These have closer plates than those from Sincapore, and smaller serratures along their edges.

In the Paumotus, which are principally coral reef islands inclosing a lagoon studded with smaller reefs, I met with a species which I have not observed elsewhere, and do not remember to have seen figured in any work on natural history. One is represented in $\mathrm{T}_{A \mathrm{~B}}$. xxxii. Fig. 6. $a, b$. The coral is of an ovate form, flatter in proportion than $F$. agariciformis, and thicker in substance, but the lamellæ are much thinner and more numerous. As I believe that these characters will prove sufficient to constitute a distinct species, I propose to call it Fungia Paumotensis. The Fungia limacina occurred frequently among the Society Islands, but I did not find it in its young and attached state. The figures represented in the accompanying plate are all taken from specimens collected in the voyage above mentioned.

In Ellis's Zoophytes (page 146.) is the following passage, VOL. XVI. 
quoted from Rumphius, in regard to the animal of $F$. agariciformis. "The more elevated folds or plaits have borders like the denticulated edges of needlework lace; these are covered with innumerable oblong vesicles formed of a gelatinous substance, which appear alive under water, and may be observed to move like an insect."

I observed these radiating folds of the animal, which secrete the lamella, and which shrink between them when the animal contracts itself on being disturbed. They are constantly moving in tremulous undulations; but the vesicles above described appeared to me to be air-vessels, placed along the edges of the folds ; and it is some confirmation of this opinion, that the vesicles disappeared when the animal was touched.

This arrangement of air-vessels would very materially assist in keeping uppermost the convex disc of the coral, and be of vital importance to the young polype at the time of separation, and subsequently, in keeping it upon the surface of its sandy bed: or if they were moved by a sudden roll of the sea, which would lift even the most ponderous, and possibly convey them a considerable distance, they would be again deposited in their natural position.

That they have no power of turning themselves I proved during a sojourn of six weeks at Tahiti, by placing a healthy specimen with its upper surface downwards, during which time it remained in the position placed, and the vitality of the points of contact with the rock upon which it was laid, was destroyed.

In Fungia limacina I have seen instances where the coral, having been accidentally placed, and permanently fixed in such unusual positions, has adapted itself to its new situation, by increasing upon its edges and forming a new convex surface.

Since writing the preceding, it has been pointed out to me that in April 1828, some months after my arrival in England 
with the specimens above mentioned, a slight notice of this subject appeared under the article Fungia in the "Encyclopedia Metropolitana"; and I regret that when I communicated to the author of that account some remarks on the corals which $I$ had collected, I was not aware that he intended to publish a notice of this discovery; as I could have given him more particulars upon the subject.

That writer states, "that they seem, when young, to be conical, and attached to some marine body, often their parent, by the base, which is contracted into a kind of stem;" and "when young, the coral has the appearance of a solitary Caryophyllia ; in this state the animal only occupies the upper surface, but when it is full grown and free it completely incloses the coral."

As long as the young Fungia retains the form of a Caryophyllia it is entirely enveloped by the soft parts of the animal; but as the upper disc of the coral spreads, and it assumes its characteristic form, the pedicle is left naked, and the soft part extends only to the line where the separation afterwards takes place. I consider the cases in which young Fungice are found fixed to the underside of others of the same species, to arise from the accidental attachment of the young polype, when detached from the ovarium of the parent, and by the motion of the water floated underneath a larger one of its own species, the edges of which were not so even as to touch the rock or coral on which it rested, at every part of its circumference. In such cases the soft parts of the older specimen would continue to cover the short stem of the younger individual, and hence its separation from its pedicle would be prevented. 


\section{EXPLANATION OF TAB. XXXII.}

Fig. 1. represents part of a large dead specimen of F. agaricifor$m i s$, upon which a great number of young ones have grown. Many remain still attached; and at $a$. are seen the footstalks from which others have been separated. 'This specimen, which is the finest that has been found, is now in the collection of Dr. Bright. A part only is represented, but enough is shown to illustrate the subject. $A$ complete drawing of this very rich specimen would be a most laborious work.

Fig. 2. $a, b$, represents two of the young of $F$. agariciformis growing attached to one of the lamellæ of a dead coral of its own species.

Fig. 3 and 4 are upper and under views of two specimens of the same species, taken soon after they had separated from their peduncles, in which the lamellæ are distinctly seen on the under surface.

Fig. 5. A larger individual of the same. In the under view the place where it was formerly attached can be clearly traced, but the part has been covered with a deposit of calcareous matter similar to the rest of the coral, and the lamellæ are no longer distinctly seen.

Fig. 6. Two views of Fungia Paumotensis in a similar state to the preceding. 

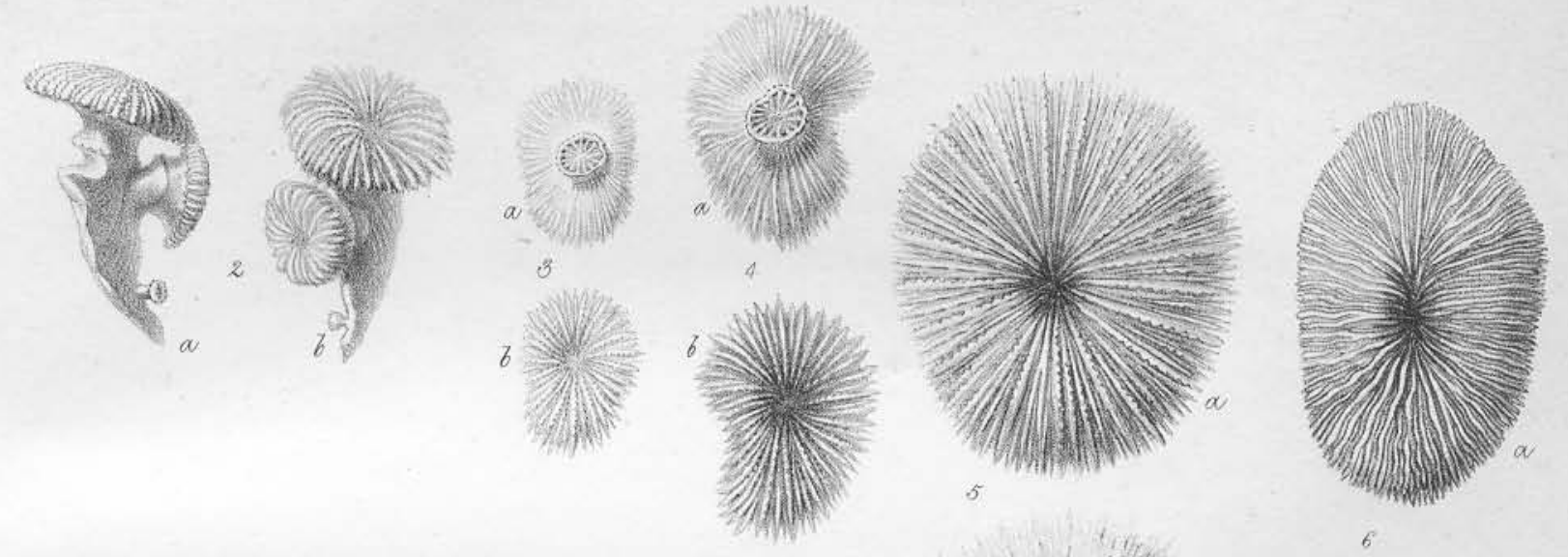
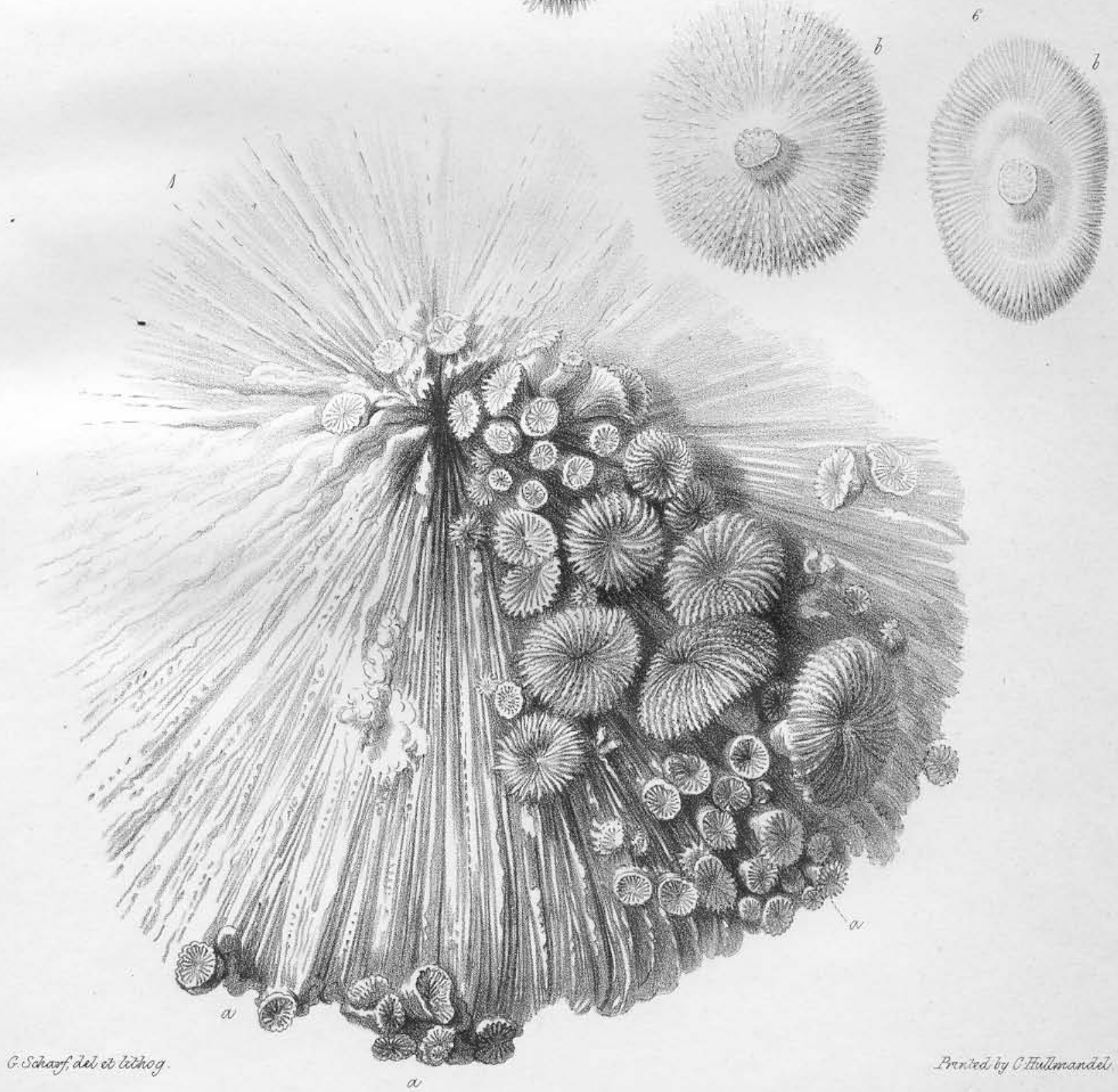